University of Nebraska - Lincoln

DigitalCommons@University of Nebraska - Lincoln

2018

Taphonomic considerations on pinworm prevalence in three Ancestral Puebloan latrines

Morgana Camacho

Alena M. Iñiguez

Karl Reinhard

Follow this and additional works at: https://digitalcommons.unl.edu/natresreinhard

Part of the Archaeological Anthropology Commons, Ecology and Evolutionary Biology Commons, Environmental Public Health Commons, Other Public Health Commons, and the Parasitology Commons

This Article is brought to you for free and open access by the Natural Resources, School of at DigitalCommons@University of Nebraska - Lincoln. It has been accepted for inclusion in Karl Reinhard Papers/ Publications by an authorized administrator of DigitalCommons@University of Nebraska - Lincoln. 


\title{
Taphonomic considerations on pinworm prevalence in three Ancestral Puebloan latrines
}

\author{
Morgana Camacho, ${ }^{1,2}$ Alena Mayo Iñiguez, ${ }^{2}$ \\ and Karl Jan Reinhard ${ }^{3}$
}

\footnotetext{
${ }^{1}$ Escola Nacional de Saúde Pública Sergio Arouca, Fundação Oswaldo Cruz, Rua Leopoldo Bulhões 1480, Manguinhos, 21041-210 Rio de Janeiro, Brazil

${ }^{2}$ Laboratório de Biologia de Tripanosomatídeos, Instituto Oswaldo Cruz, Fundação Oswaldo Cruz, Avenida Brasil 4365, Manguinhos, 21040360 Rio de Janeiro, Brazil

3 Pathoecology Laboratory, School of Natural Resources, University of NebraskaLincoln, 101 Hardin Hall, 3310 Holdrege Street, Lincoln, NE 68583-0961, USA

Corresponding author - A.M. Iñiguez, alena@ioc.fiocruz.br
}

Email addresses: M. Camacho morganacamacho88@gmail.com, K.J. Reinhard kreinhard1@unl.edu

\begin{abstract}
For archaeological studies it is always necessary to consider taphonomic factors that could have influenced in ancient material preservation. Parasite eggs are usually highly degraded in ancient sites dated from all periods of time and taphonomic factors are mentioned to explain absence and low quantity of eggs found. In this study, we compare parasite egg recovery of three Great House latrines: two from Aztec Ruins (Rooms 219 and 225) and one from Salmon Ruins. We compared through statistical regression the recovery of eggs with the abundance of two classes of decomposers: mites and nematodes. These microorganisms have relation with nematode
\end{abstract}

Published in Journal of Archaeological Science: Reports 20 (2018) 791-798

DOI: 10.1016/j.jasrep.2018.06.024

Copyright (C) 2018 Elsevier Ltd. All rights reserved. Used by permission.

Submitted 11 December 2017; revised 4 June 2018; accepted 17 June 2018; published 2 July 2018. 
larvae and parasites remains degradation, respectively, mostly in moist environments. Pinworm was the only parasite found in the sites studied. Prevalences were 32.8\% at Salmon Ruins, 72.7\% at Aztec Ruins Room 225 and 14.3\% at Room 219. Egg preservation was considered good at Salmon Ruins and Aztec Ruins Room 225. At Room 219, the eggs were badly preserved and there was a significant statistical correlation with mites (multiple $\mathrm{r}(18)=0.64 / P=0.002$ ). This correlation could indicate that mites could be involved in preservation, and consequently that pinworm prevalence in this latrine is underestimated. Abiotic factors such as humidity could have possibly favored the biological relation. Considering the extreme egg degradation at Room 219, it is not possible to strictly compare parasite data with other Ancestral Pueblo sites, even with Room 225, located at the same site. Room 225 prevalence is the highest found in Ancestral Pueblo sites until now. Taphonomic analysis shows that decomposers operated at different levels of severity, despite the latrines' close location.

Keywords: Taphonomy, Mites, Enterobius vermicularis, Coprolites

\section{Introduction}

Taphonomy was firstly defined by Efremov (1940) as the study of all of aspects involved in the transition of animal remains from the biosphere into the lithosphere. Anthropologists study the degradation of biological remains after they are deposited in archaeological context (Sorg and Haglund, 2002). After the death of any given organism, it becomes a new microenvironment, serving as a food source for several decomposers. The action of these decomposers and the assimilation of the resources provided by the organism deposited in a locale, depend on factors such as climate, humidity, $\mathrm{pH}$, soil, and others that influence the intensity of degradation (Lyman, 2010; Sorg and Haglund, 2002).

The taphonomy of parasite remains in archaeological contexts has been addressed by some authors beginning with Reinhard et al. (1986). In this study, the authors evaluated aspects of sample processing, sediment $\mathrm{pH}$ and fungal action in degrading parasite eggs. They found that fungal proliferation can degrade eggshells and embryos, thus compromising parasitological diagnosis in ancient material. More recently, parasite egg taphonomy was addressed in Morrow et al. (2014, 2016) and Rácz et al. (2015) papers. They mentioned specific characteristics of eggs morphologies and environmental conditions that make certain egg types more susceptible to decay than others. The factors they discussed included water saturation of sediments 
and humidity as main factors that can result in differential egg type preservation, even in samples from the same site (Morrow et al., 2014, 2016; Rácz et al., 2015).

Morrow et al. (2016) define five sets of factors that can destroy parasite eggs: abiotic, contextual, anthropogenic, organismal and ecological. Abiotic refers to temperature, soil, $\mathrm{pH}$, humidity and other nonliving factors. Contextual refers to the archaeological material that was analyzed to obtain the parasitological information. Anthropogenic refers to the human manipulation of the parasite source from the moment of its deposition until the collection, transportation and analysis by the researcher. Organismal refers to the individual biological characteristics of each parasite, for example, egg resistance, fecundity and life cycle. Ecological, refers to the decomposer organisms that are part of the environment from which the archaeological material came from.

Ancestral Pueblo archaeological sites exhibit excellent coprolite preservation (Reinhard, 2008; Reinhard and Bryant, 2008). These sites are located in dry environments, recognized as one of the best places to preserve parasite remains (Reinhard et al., 1986). Among the sets defined by Morrow et al. (2016), the Organismal and Ecological conditions are the most relevant to the study in these sites. Organismal conditions to be considered involve the resistance of thickwalled eggs such as whipworm compared to thin-walled eggs such as pinworm (Jaeger and Iñiguez, 2014). Hatched nematode larvae, such as those from hookworms, are most susceptible to decay. Ecological conditions to be considered include decomposer organisms such as free-living nematodes, mites, fungi, bacteria and insects. The taphonomy experience as of 2012 was summarized by Reinhard who wrote: "In our combined experience there is significant decomposition of remains from latrines by fungi and arthropods as described by Reinhard et al. (1986). In contrast, coprolites exhibit the best preservation. Mummies (Reinhard and Urban, 2003) and sediments from sacra (Fugassa et al., 2008) also show excellent preservation of delicate eggs" (Reinhard et al., 2013).

From Ancestral Pueblo sites, coprolites have been recovered from caves and open site latrines (Reinhard, 2008). For many years, researchers have noticed that pinworm eggs from open sites are more poorly preserved than those recovered from caves. This was especially true for Chaco Great House latrines (Reinhard, 1992; Reinhard and Clary, 1986). Mites are arachnids, usually microscopic, that possess 
mouthparts specialized to the various feeding habits (Roberts et al., 2013a). These are organismal taphonomic factors that are frequently seen in Ancestral Pueblo coprolite samples (Reinhard et al., 2012). Mites have been associated with free-living nematode predation. Experimental studies concluded that some mites show predation preference for nematode larvae (Epsky et al., 1988; Martikainen and Huhta, 1990; Muraoka and Ishibashi, 1976; Read et al., 2006; Santos et al., 1981). Despite this relation, the role of mites as a taphonomic factor that interferes in parasite egg preservation and a statistical correlation between the presence of mites and egg degradation is not yet established in the literature. We are assessing that relationship in this paper.

Nematode larvae are also frequently found in Ancestral Pueblo coprolite samples (Paseka, 2010). In the literature, some nematode larvae are associated with soil protozoa decomposition (Georgieva et al., 2005), but there is no record of its relation with parasite egg degradation. In order to verify if there is a correlation between the presence of mites and nematode larvae with parasite egg degradation, we focus on the recovery of pinworm eggs in three Great House latrines compared to mites and nematode larvae per gram of coprolite.

\section{Materials and methods}

Coprolites from Salmon Ruins and Aztec Ruins Ancestral Pueblo archaeological sites were collected to perform this study (Fig. 1). Salmon Ruins and Aztec Ruins represent relatively recent occupations of the Chaco Culture and are dated between 1000 and 1200 years Anno Domini (AD), period when the Pueblo II and Pueblo III were present in this region (Gwinn Vivian and Hilpert, 2012).

Salmon Ruins is identified as a Chaco outlier community and it is located by the San Juan River, in Bloomfield, New Mexico (Fig. 1). The main ruin is a Great House built with 275 rooms and three storyhigh (Fig. 2A). It was built in relatively short time, between 1088 and $1100 \mathrm{AD}$, and abandoned by the Chacoan occupation around the year 1130 AD. The Great House was occupied a second time by Mesa Verde Ancestral Puebloans after $1180 \mathrm{AD}$ leading to the remodeling of the site. In the second occupation, the population used the Great House as a burial place, storage, ritual place and latrine (Gwinn Vivian and 

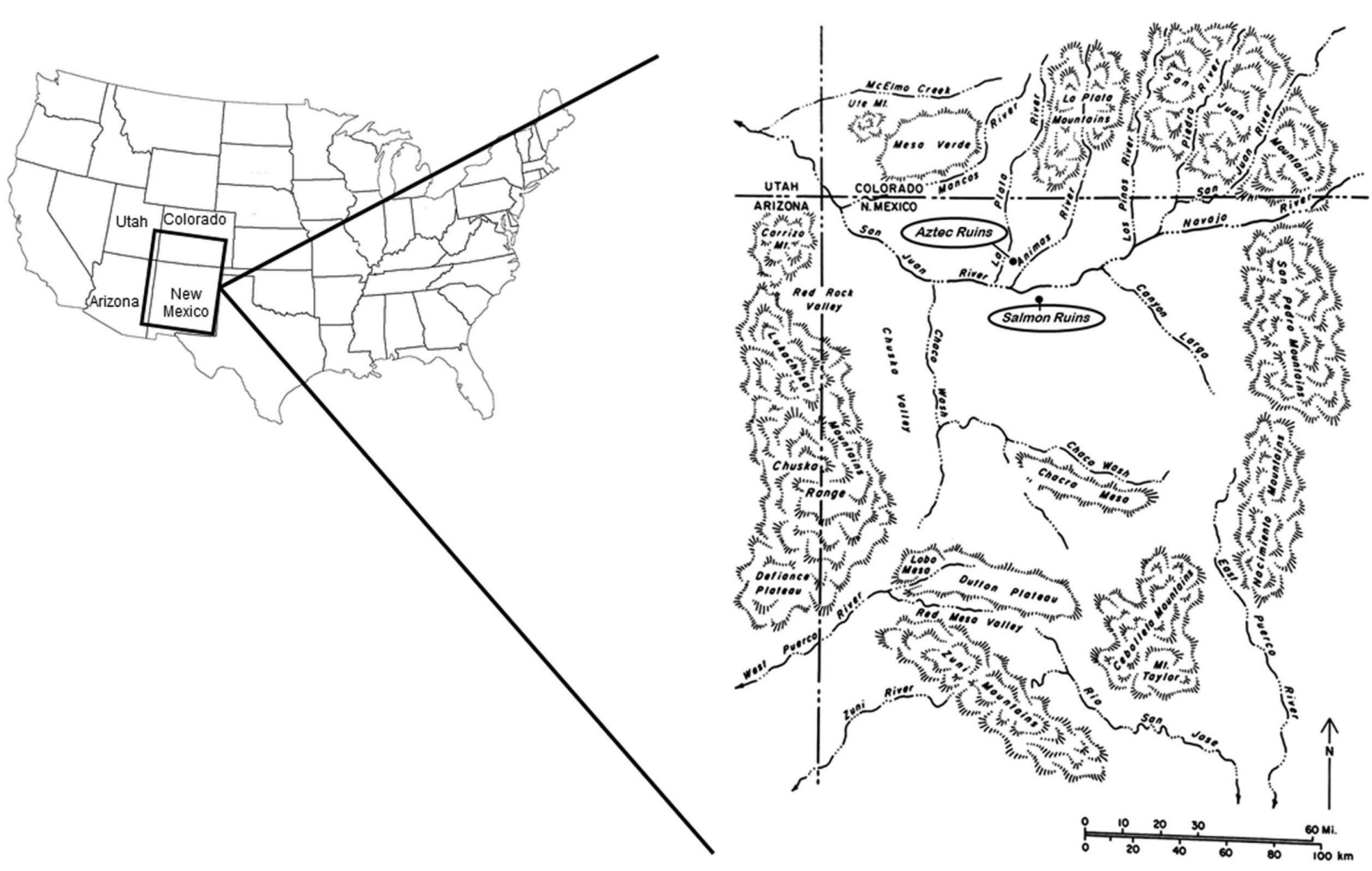

Fig. 1. Geographical location of Aztec Ruins and Salmon Ruins. Modified from Gwinn Vivian (1990).

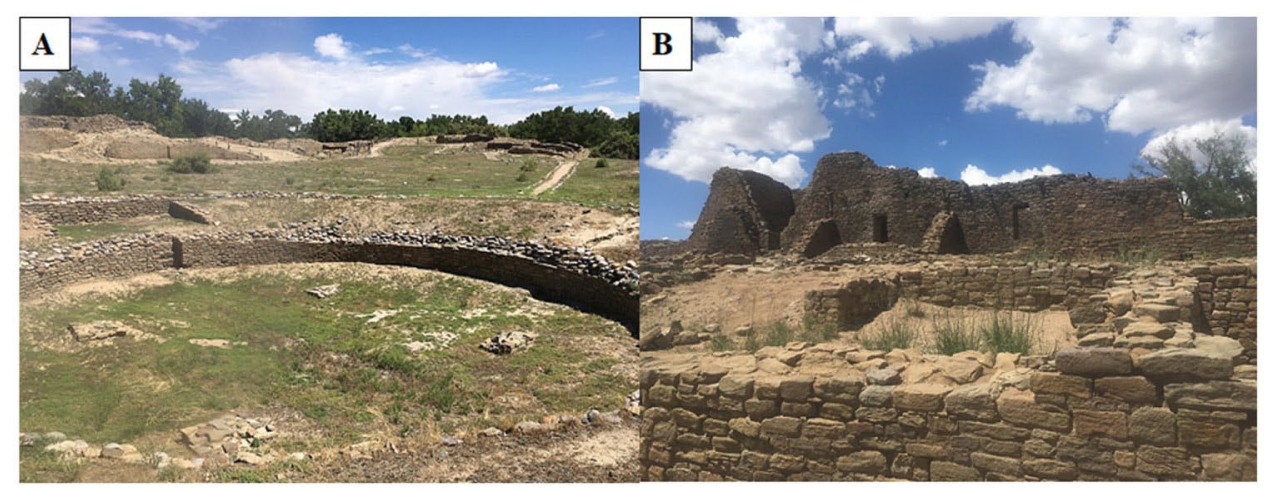

Fig. 2. A and B - A: View of the remaining ruins of Salmon Ruins. B: View of the remaining ruins of Aztec Ruins. Photos: Morgana Camacho.

Hilpert, 2012). The site used to have three latrines. However, two of them were destroyed due to a fire. Room $62 \mathrm{~W}$ is the last remaining latrine where 67 samples were collected for this study.

Aztec Ruins is an archaeological Ancestral Pueblo site located near the Animas River in Aztec, New Mexico (Fig. 1). It was originally built by the Chaco Canyon Culture, between 1000 and 1200 years AD. It is 
considered as a Chaco outlier community characterized by a set of constructions. The larger and most studied of these constructions is the West Ruin, a Great House with 400 rooms, used by this population as a regional administrative and religious center (Fig. 2B). These constructions were abandoned by the Chacoans. After the abandonment, Mesa Verde Ancestral Puebloans migrated to this complex and occupied the site. These Ancestral Puebloans used the West Ruin as ritual and burial place, to store their agricultural produce and as latrine, but not as habitation. The Mesa Verdean occupation is signaled by the several ceramic styles and burials found in the West Ruin. Archaeologists identified 2 latrines, Rooms 219 and 225, dated from the second occupation period (Room 219-1182-1250 AD/Room 225-1185-1253 AD) (Schillaci and Stojanowski, 2002; Gwinn Vivian and Hilpert, 2012).

Coprolite samples from both latrines were collected to perform this study. Twenty-one samples from Room 219 and 22 samples from Room 225. The samples were collected using disposable materials and tools for each coprolite as well as personal protection equipment. The coprolites were stored in individual airtight plastic bags and transported at environmental temperature to the Palynology Lab, School of Natural Resources, University of Nebraska-Lincoln, USA, for further analysis.

Samples were weighed and $2 \mathrm{~g}-3 \mathrm{~g}$ of each coprolite were selected for analysis. Samples were rehydrated in $0.5 \%$ trisodium phosphate $\left(\mathrm{Na}_{3} \mathrm{PO}_{4}\right.$ ) aqueous solution during $24 \mathrm{~h}$ in individual plastic tubes with screw caps (Callen and Cameron, 1960; Camacho et al., 2018). During this process, one Lycopodium tablet containing 12,500 spores (Batch No. 12496) was added for each gram of sample, for quantification (Reinhard et al., 2012). Two-hundred microliters of $40 \%$ of hydrochloric acid $(\mathrm{HCl})$ were added to enable the dissolution of the tablets and the dissociation of some mineralized coprolites (Reinhard et al., 2008).

After the rehydration, the tubes were vortexed for $40 \mathrm{~s}$ and the samples were immediately washed through $250 \mu \mathrm{m}$ mesh placed in $50 \mathrm{ml}$ beakers, in order to separate the macro from the microresidues. Distilled water jets and metal minispatulas were used to disaggregate the macroresidues retained in the mesh. Alcohol was added to the samples in order to avoid microorganisms proliferation. The macroresidues were transferred to individual filter papers, left to dry at environmental temperature and stored in whirlpak plastic bags for future analyses. 
The microresidues in the beakers were pipetted and transferred back into the tubes. Drops of each sample were pipetted to microscope slides, mixed with glycerin and cover-slipped. The samples were analyzed in a light microscope at $100 \times$ and photographs were taken at $400 \times$ magnification. A minimum of 200 Lycopodium spores was quantified for each sample, along with parasite eggs (Morrow, 2016), mites and nematode larvae.

To calculate the eggs, mites and nematode larvae per gram of coprolite (EPG/MPG/LPG), the following formula was applied (Pearsall, 2016): $\mathbf{E P G}=[(\mathbf{p} / \mathbf{m}) \times \mathbf{a}] / \mathbf{v}$, where $\mathbf{p}$ is the number of parasite eggs counted, $\mathbf{m}$ is the number of Lycopodium spores counted, $\mathbf{a}$ is the number of Lycopodium spores added and $\mathbf{v}$ is the quantity of sample processed. A statistical regression $(P<0.05)$ was applied in order to stablish the possible positive correlation between the egg degradation and mites/larvae per gram of coprolite. The correlation was made by comparing the EPG data separately with the MPG data and then with the LPG data. Samples that were negative for mites and larvae were excluded from the analysis.

\section{Results}

Pinworm was the only parasite recovered from the coprolites. In Salmon Ruins, 22 of the 67 samples were positive, representing 32.8\% of prevalence. Aztec Ruins showed extremely different results, when comparing the two latrines. At Room 219, three of the 21 samples were positive for Enterobius vermicularis eggs while at Room 225, 16 of the 22 samples had eggs of this parasite, with prevalences of $14.3 \%$ and $72.7 \%$, respectively. Egg preservation was variable at the sites. In Salmon Ruins, eggs were generally well preserved, however, they exhibited degradation of eggshells and absence of larvae in eight samples (Fig. 3A-F). In Aztec Ruins Room 219, pinworm eggs were badly preserved with highly degraded eggshells, no larvae preserved and one of the eggs was only half preserved (Fig. 4A-C). In Aztec Ruins Room 225 preservation was excellent, with both eggshells and larvae intact (Fig. 5A-F).

There was a variety of mites and larvae, demonstrated in Figs. 6 and 7. In Salmon Ruins, 62 samples had mites and only four of the 67 samples had larvae. In Aztec Ruins Room 219, 20 samples had mites 


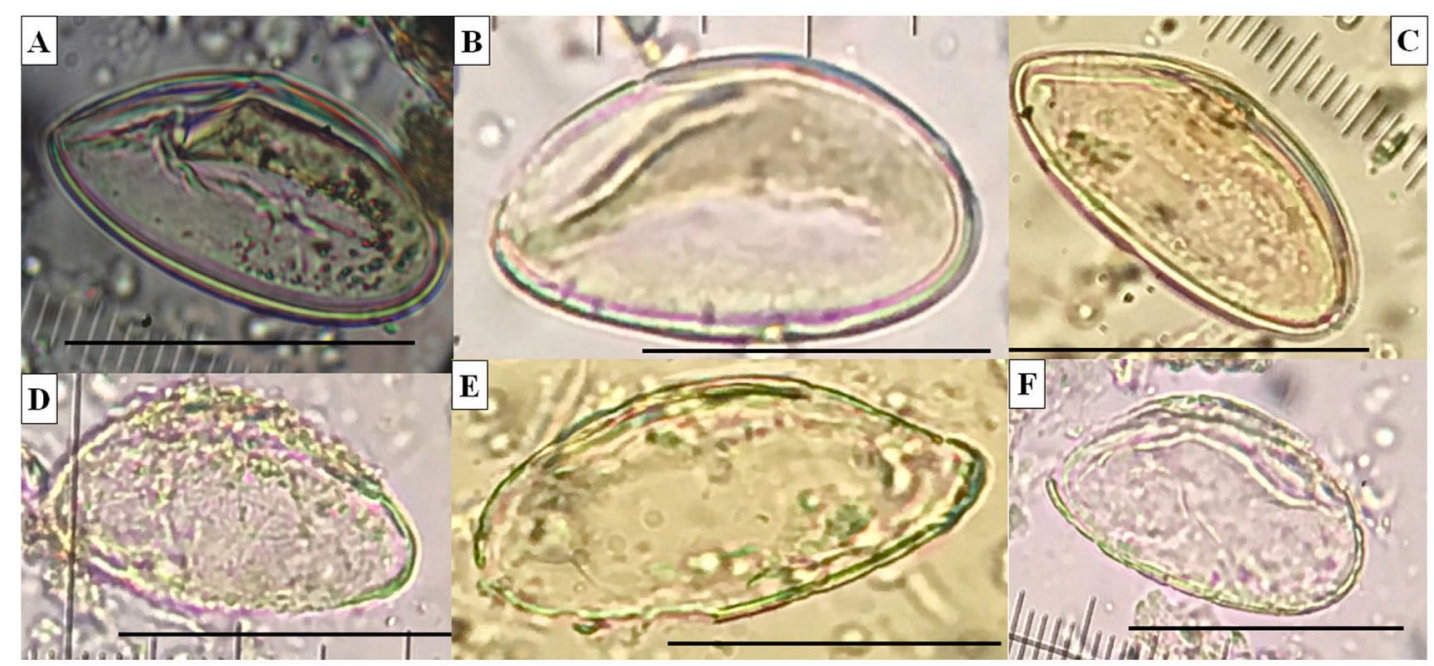

Fig. 3. A-F - Pinworm eggs recovered from Salmon Ruins. A-C: Eggs with excellent preservation, showing preserved eggshells and larvae. D-F: Eggs with some level of degradation showing degraded eggshells. Scale-bars $=50 \mu \mathrm{m}$.

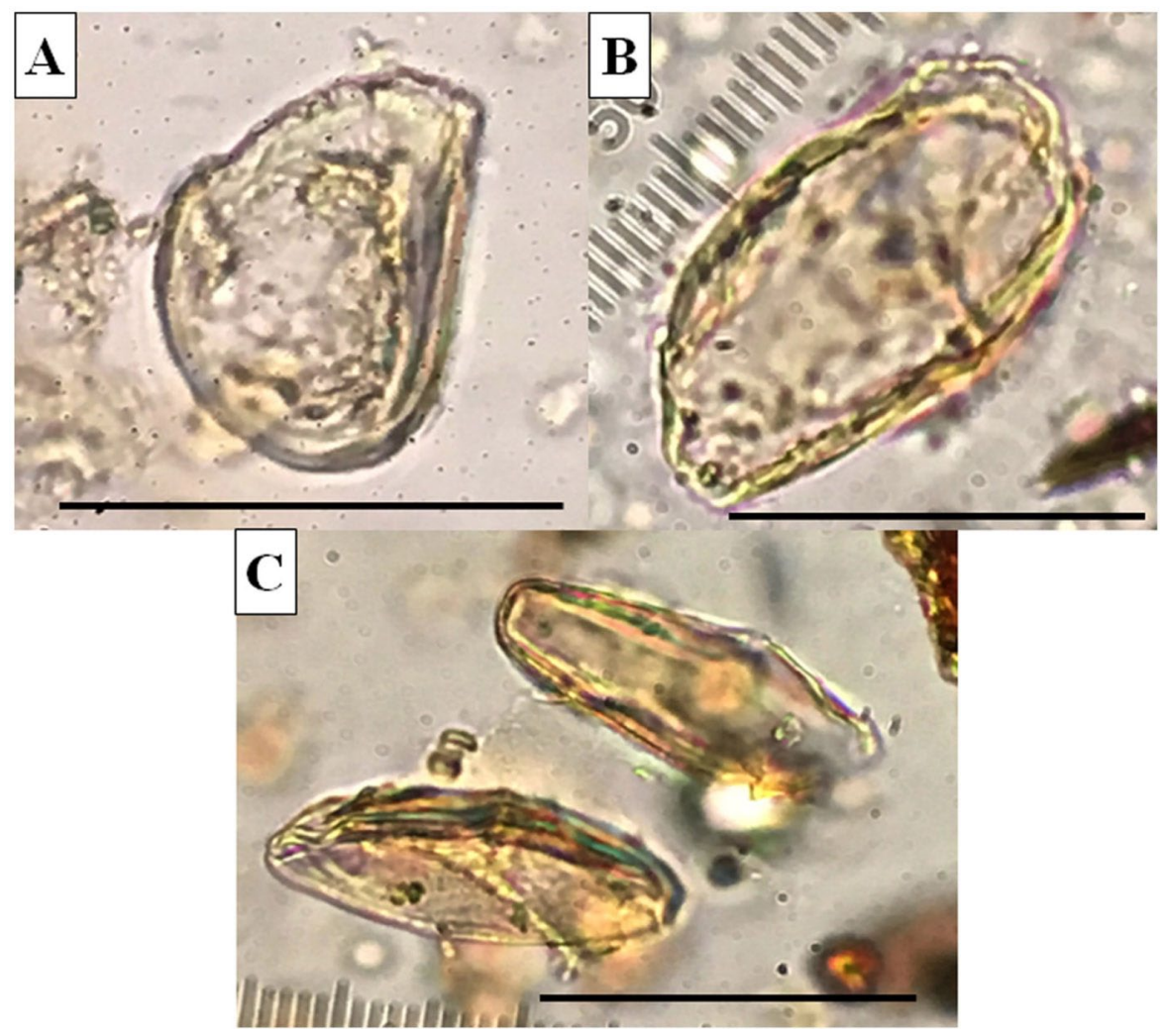

Fig. 4. A-C - Pinworm eggs recovered from Aztec Ruins Room 219. All eggs presented poor preservation. A: Half of a pinworm egg that seems to have been abraded by mite's chelicerae. B: Eggshell shows high level of degradation that can compromise parasitological diagnosis. C: Two pinworm eggs with compromised morphology. Scale-bars $=50 \mu \mathrm{m}$. 


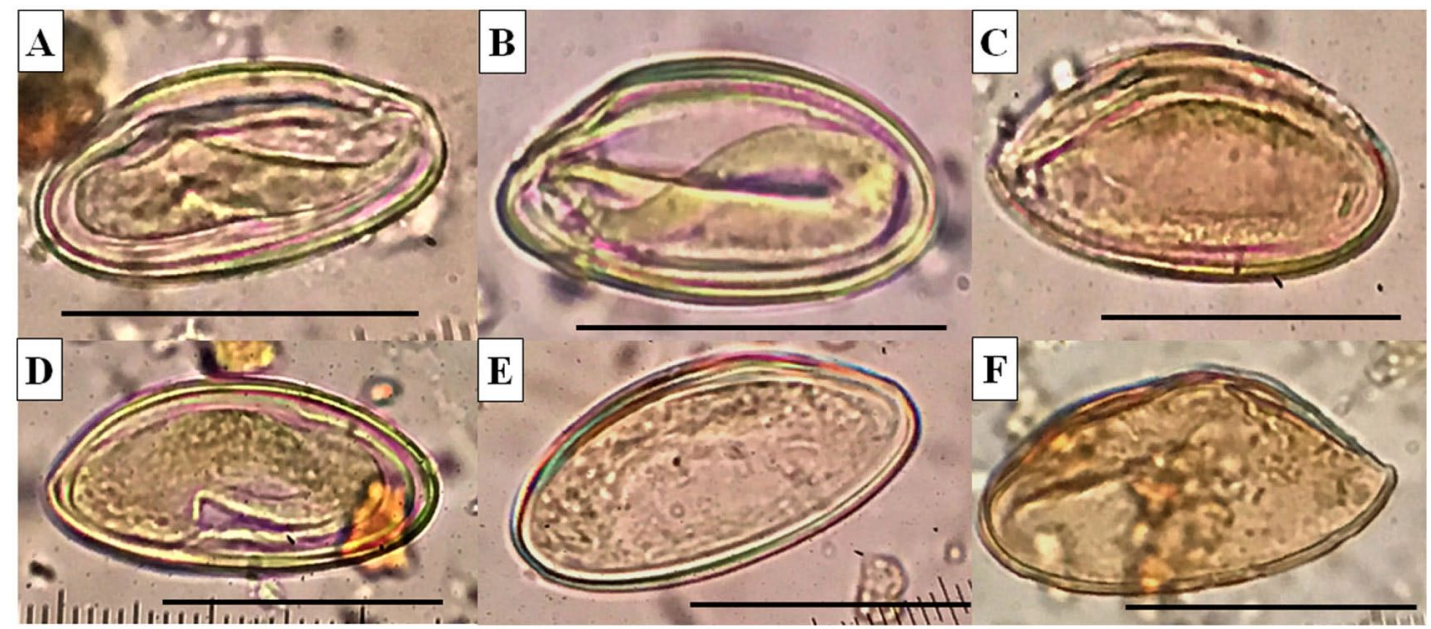

Fig. 5. A-F - Pinworm eggs recovered from Aztec Ruins Room 225 presenting excellent preservation. All eggs showed preserved eggshells and larvae. Scalebars= $50 \mu \mathrm{m}$.

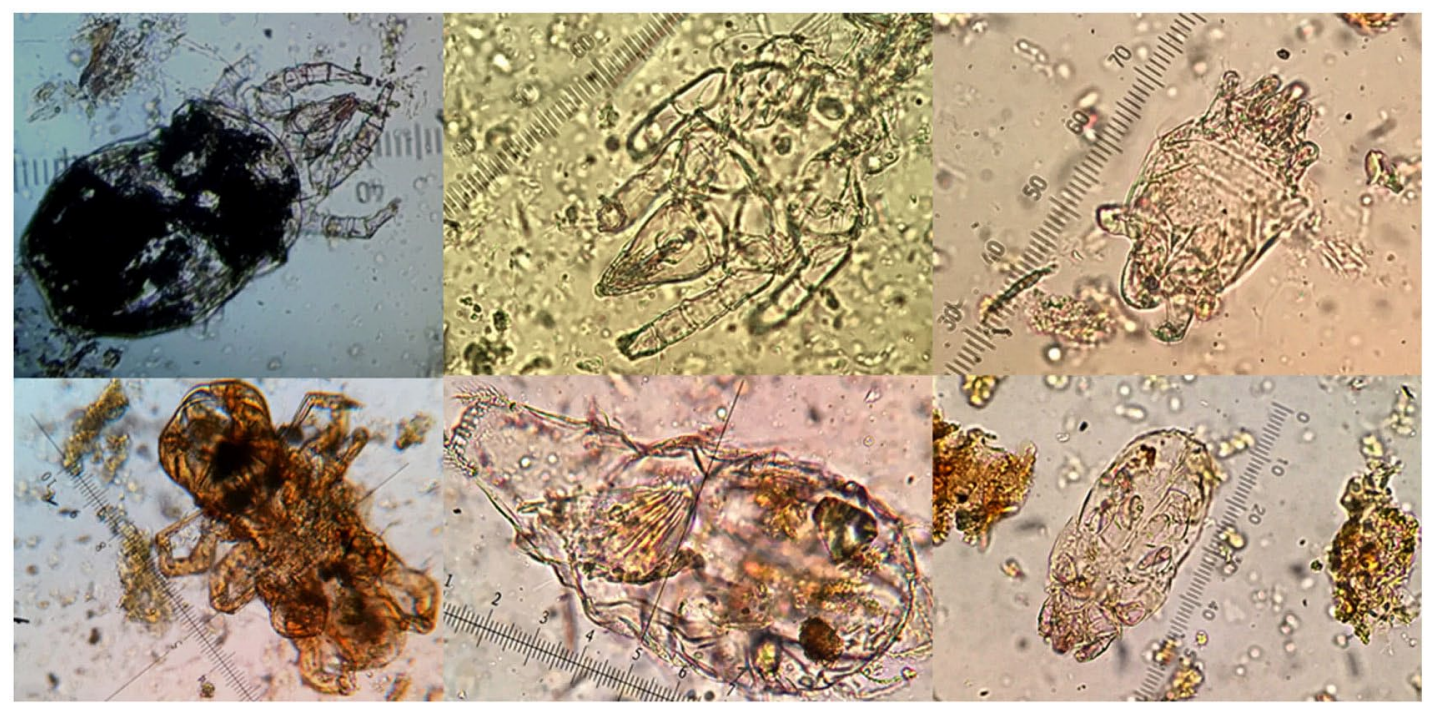

Fig. 6. Mites found in coprolites from all sites.

and only three from 21 samples had larvae. In Aztec Ruins Room 225, 15 samples had mites and 14 from 22 samples had larvae. Estimation of eggs, mites and larvae per gram of coprolite (EPG/MPG/LPG) for Salmon Ruins and Aztec Ruins Rooms 219 and 225 are shown in Tables 1-3. Statistical regression was applied in order to establish the positive or negative correlation between egg degradation and the number of MPG and LPG. For Salmon Ruins (multiple r(60)=0.09/ $P=0.442$ ) and Aztec Ruins Room 225 (multiple $\mathrm{r}(13)=0.26 / P=0.341$ ) the correlation between pinworm egg degradation and mites per gram 


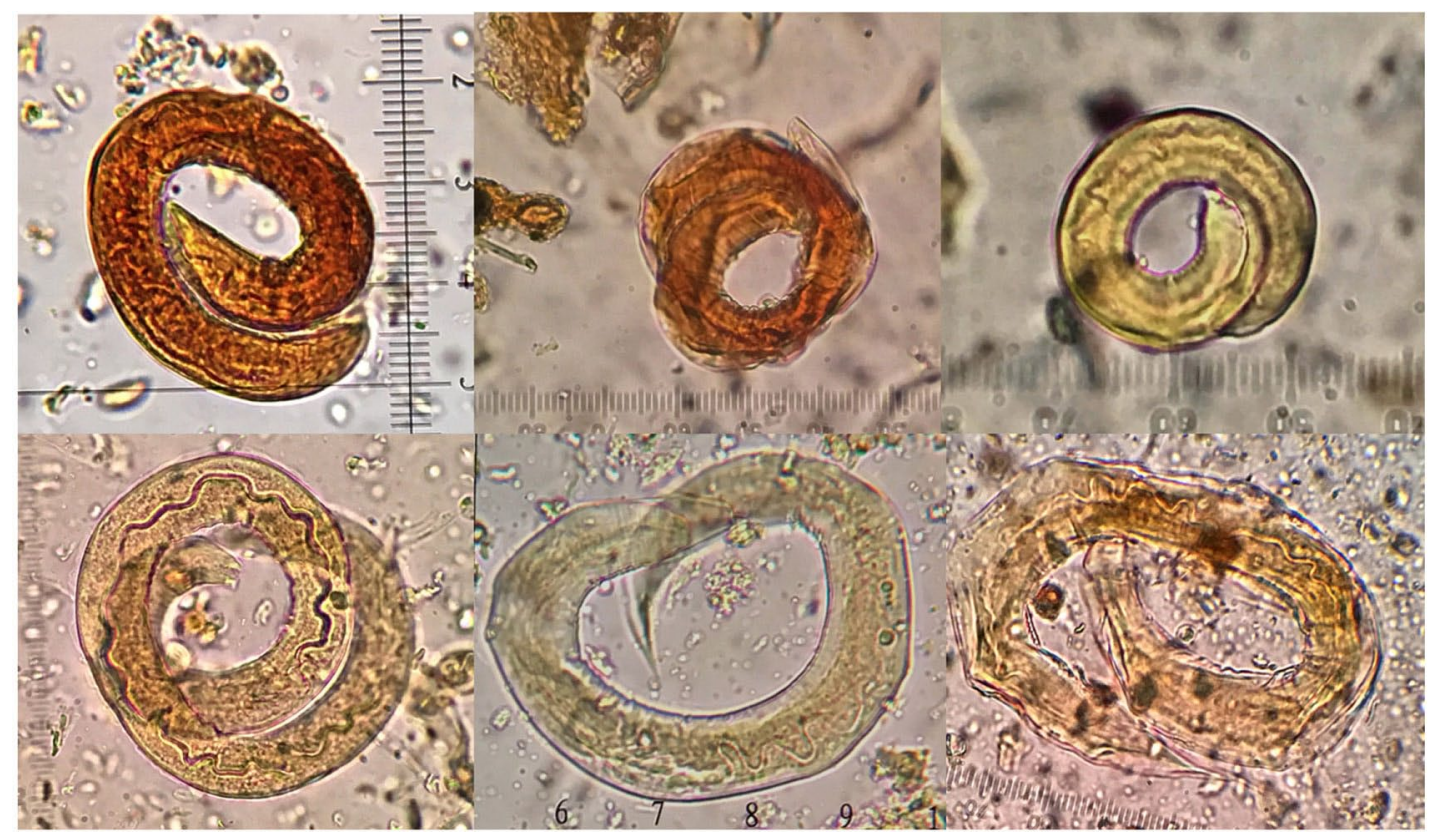

Fig. 7. Larvae found in coprolites from all sites.

of coprolite was not statistically significant. However there was a statistically significant correlation between egg degradation and MPG in Aztec Ruins Room 219 (multiple r(18)=0.64/P=0.002).

The correlation between egg degradation and the number of LPG of coprolite was calculated only for Aztec Ruins 225, since in Salmon Ruins and Aztec Ruins Room 219 only a few samples presented larvae. However, this correlation was not statistically significant (multiple $r(12)=0.13 / P=0.635)$.

\section{Discussion}

Enterobius vermicularis eggs were the only parasitological finding in the samples analyzed. Pinworm females deposit eggs in the host's perianal region and for this reason, eggs are not usually found in the fecal matter (Rey, 2008; Reinhard and Pucu, 2014; Roberts et al., $2013 \mathrm{~b})$. When the feces pass through the perianal area, some of the eggs attach to it and this is what can be recovered. According to Rey (2008) and Roberts et al. (2013b), only 5-10\% of fecal samples present eggs. This makes the fecal analysis unsuitable for diagnosing pinworm infection. Pinworm eggs are also considered to be fragile and 
Table 1 Results of eggs, mites and larvae per gram of coprolites from Salmon Ruins.

\begin{tabular}{|c|c|c|c|c|c|c|c|}
\hline Sample ID & EPG & MPG & LPG & Sample ID & EPG & MPG & LPG \\
\hline 1 & 168,77 & 0,00 & 0,00 & 41 & 0,00 & 857,78 & 0,00 \\
\hline 2 & 53,35 & 53,35 & 106,70 & 43 & 0,00 & 1062,50 & 0,00 \\
\hline 3 & 1963,98 & 374,09 & 0,00 & 44 & 0,00 & 645,54 & 0,00 \\
\hline 4 & 112,87 & 338,62 & 0,00 & 45 & 0,00 & 307,88 & 0,00 \\
\hline 5 & o,oo & 464,58 & 0,00 & 46 & 0,00 & 2647,78 & 0,00 \\
\hline 6 & 0,00 & 286,19 & 57,24 & 47 & 0,00 & 2373,42 & o,oo \\
\hline 7 & 79,45 & 436,99 & 39,73 & 48 & o,oo & 172,55 & 0,00 \\
\hline 8 & 0,00 & 1717,62 & 0,00 & 49 & 262,40 & 1259,53 & 0,00 \\
\hline 9 & 0,00 & 364,08 & o,oo & 50 & o,oo & 375,00 & 0,00 \\
\hline 10 & 0,00 & 112,85 & 112,85 & 51 & 0,00 & 892,86 & 0,00 \\
\hline 11 & 0,00 & 334,11 & 0,00 & 52 & 0,00 & 1610,25 & 0,00 \\
\hline 12 & o,oo & 784,02 & 0,00 & 53 & 0,00 & o,oo & $\mathrm{o}, \mathrm{OO}$ \\
\hline 13 & 242,79 & 776,94 & 0,00 & 54 & 0,00 & 369,46 & 0,00 \\
\hline 14 & o,oo & 96,79 & 0,00 & 55 & 0,00 & 475,91 & 0,00 \\
\hline 15 & 336,72 & 673,44 & 0,00 & 56 & 586,30 & 820,83 & 0,00 \\
\hline 16 & 164,00 & 765,33 & 0,00 & 57 & 296,01 & 532,82 & 0,00 \\
\hline 17 & 53,58 & 160,73 & 0,00 & 58 & 109,91 & 164,86 & o,oo \\
\hline 18 & 2097,67 & 524,42 & 0,00 & 59 & 0,00 & 846,88 & 0,00 \\
\hline 19 & o,oo & 1725,72 & 0,00 & 60 & 0,00 & 693,82 & 0,00 \\
\hline 20 & o,oo & 435,32 & o,oo & 61 & o,oo & 1147,34 & 0,00 \\
\hline 21 & 7345,25 & 100,62 & 0,00 & 62 & 123,76 & 61,88 & 0,00 \\
\hline 22 & o,oo & 1379,54 & 0,00 & 63 & $\mathrm{o}, \mathrm{oo}$ & 229,27 & 0,00 \\
\hline 23 & 0,00 & 60,97 & 0,00 & 64 & o,oo & 777,78 & 0,00 \\
\hline 24 & 54,55 & 981,93 & 0,00 & 65 & 0,00 & 56,31 & 0,00 \\
\hline 25 & 0,00 & 673,84 & 0,00 & \multirow{16}{*}{\multicolumn{4}{|c|}{$\begin{array}{l}\text { OBS: Samples 42, } 66 \text { and } 67 \text { presented zero } \\
\text { values for EPG, MPG and LPG. }\end{array}$}} \\
\hline 26 & 0,00 & 124,38 & $\mathrm{o}, \mathrm{oo}$ & & & & \\
\hline 27 & 0,00 & 275,08 & 0,00 & & & & \\
\hline 28 & 0,00 & 530,22 & 0,00 & & & & \\
\hline 29 & 0,00 & 2339,79 & 0,00 & & & & \\
\hline 30 & o,oo & 2216,64 & 0,00 & & & & \\
\hline 31 & 371,29 & 1670,79 & 0,00 & & & & \\
\hline 32 & o,oo & 175,97 & o,oo & & & & \\
\hline 33 & 0,00 & 236,91 & 0,00 & & & & \\
\hline 34 & 60,10 & 1442,31 & 0,00 & & & & \\
\hline 35 & 759,35 & 2978,97 & 0,00 & & & & \\
\hline 36 & 121,34 & 364,03 & 0,00 & & & & \\
\hline 37 & 0,00 & 174,20 & 0,00 & & & & \\
\hline 38 & 58,64 & 938,17 & 0,00 & & & & \\
\hline 39 & 0,00 & 121,94 & 0,00 & & & & \\
\hline 40 & 0,00 & 1125,59 & 0,00 & & & & \\
\hline
\end{tabular}


Table 2 Results of eggs, mites and larvae per gram of coprolites from Aztec Ruins Room 219.

\begin{tabular}{|c|c|c|c|}
\hline Sample identification & EPG & MPG & LPG \\
\hline 1 & 294,813 & 183,96 & 0,00 \\
\hline 2 & 61,27 & 1593,14 & 0,00 \\
\hline 4 & 0,00 & 1573,30 & 58,27 \\
\hline 5 & 0,00 & 254,07 & 0,00 \\
\hline 6 & 0,00 & 117,92 & 0,00 \\
\hline 7 & 0,00 & 1611,40 & 0,00 \\
\hline 8 & 0,00 & 1010,64 & 53,19 \\
\hline 9 & 0,00 & 1562,50 & 0,00 \\
\hline 10 & 0,00 & 918,6 o & 0,00 \\
\hline 11 & 60,68 & 1881,07 & 0,00 \\
\hline 12 & 0,00 & 163,21 & 0,00 \\
\hline 13 & 0,00 & 183,21 & 0,00 \\
\hline 14 & 0,00 & 430,30 & 0,00 \\
\hline 15 & 0,00 & 1973,68 & 0,00 \\
\hline 16 & 0,00 & 1111,32 & 0,00 \\
\hline 17 & 0,00 & 1710,62 & 53,46 \\
\hline 18 & 0,00 & 56,63 & 0,00 \\
\hline 19 & 0,00 & 1494,71 & 0,00 \\
\hline 20 & 0,00 & 633,60 & 0,00 \\
\hline 21 & 0,00 & 1701,16 & 0,00 \\
\hline
\end{tabular}

OBS: Sample 3 presented zero values for EPG, MPG and LPG.

are not usually found in ancient samples analyses (Jaeger and Iñiguez, 2014; Reinhard et al., 2016). However, despite these assumptions, in the studied Ancestral Pueblo sites, we were able to recover the highest prevalences of infection and to apply quantification methods to estimate EPG of coprolite.

There are other helminths that produce more resistant eggs, such as Ascaris sp. and Trichuris trichiura, which exhibit at least three layers of eggshell (Roberts et al., 2013c, 2013d). Pinworm eggs have a thin eggshell (Roberts et al., 2013b) and its presence in the absence of both more resistant eggs or fragile eggs, like those from ancylostomids, indicates that possibly this was the only helminth infection in these populations (Reinhard and Pucu, 2014).

Considering the Morrow et al. (2016) taphonomy factors, abiotic, contextual and anthropogenic factors could have contributed to the preservation of the parasitological evidence. These sites are located in 
Table 3 Results of eggs, mites and larvae per gram of coprolites from Aztec Ruins Room 225.

\begin{tabular}{lccc} 
Sample identification & EPG & MPG & LPG \\
\hline 1 & 117,53 & 2115,51 & 0,00 \\
2 & 0,00 & 0,00 & 1334,60 \\
3 & 199,47 & 49,87 & 50,20 \\
4 & 0,00 & 60,67 & 1838,24 \\
5 & 0,00 & 486,17 & 3047,26 \\
6 & 60,57 & 0,00 & 975,61 \\
7 & 0,00 & 362,27 & 0,00 \\
8 & 0,00 & 0,00 & 52,08 \\
9 & 1639,19 & 93,67 & 0,00 \\
10 & 1335,47 & 44,52 & 1620,37 \\
11 & 783,76 & 663,18 & 62,50 \\
12 & 842,64 & 105,33 & 0,00 \\
13 & 0,00 & 0,00 & 509,05 \\
14 & 56,89 & 455,15 & 175,23 \\
15 & 72,52 & 0,00 & 61,88 \\
16 & 89,24 & 2275,65 & 223,10 \\
17 & 52,72 & 105,43 & 0,00 \\
18 & 98,52 & 0,00 & 0,00 \\
19 & 403,99 & 101,00 & 0,00 \\
20 & 116,43 & 174,65 & 0,00 \\
21 & 415,74 & 0,00 & 6463,41 \\
22 & 171,89 & 114,59 & 925,93 \\
\hline & & &
\end{tabular}

dry environments, considered as one of the most favorable conditions to preserve parasite remains (Reinhard et al., 1986). The dry climate favored the preservation of coprolites, which are the context of the parasitological findings. Coprolites are feces preserved by desiccation or mineralization and provide protection to the parasite remain (Bryant and Reinhard, 2012). Specific to our sites, room construction is a contextual factor that could have enhanced preservation. The latrines were isolated rooms, built with thick stone walls and pine wood ceilings, used only for trash disposal and as latrines (Gwinn Vivian and Hilpert, 2012). Besides this fact, the room architecture did not allow that water, wind or any other abiotic factor could get in contact with the fecal matter. This explains for example, why Aztec Ruins Room 225 pinworm eggs are so well preserved. The latrine presents, until today, the same conditions that it had when constructed, including the preserved original ceiling (Fig. 8) (Lister and Lister, 1987). 


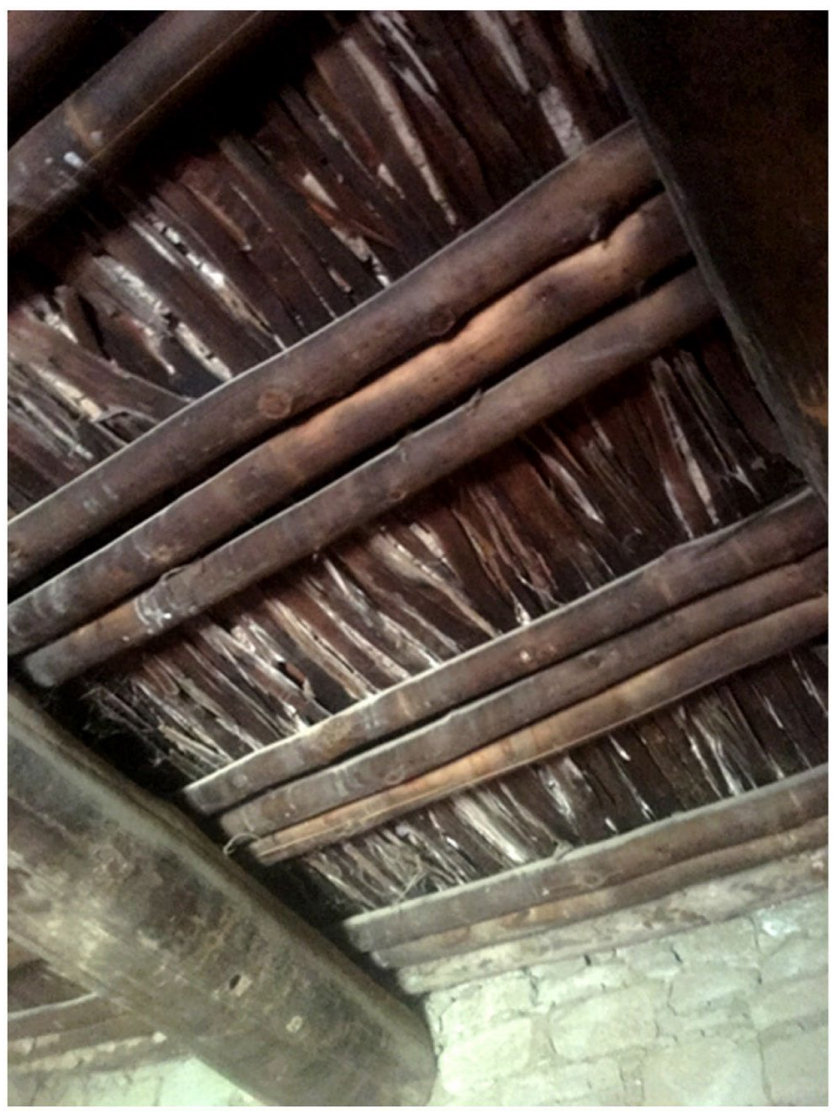

Fig. 8. Detail of one of Aztec Ruins' room ceiling showing the complex organization of the wood that probably resulted in the protection of the coprolites and hampered the parasite egg degradation in Room 225. Photo: Morgana Camacho.

Ecological factors are the main taphonomic element affecting egg preservation. Aztec Ruins Room 225 shows large numbers of LPG but lower amounts of MPG. An excellent preservation of pinworm eggs was observed (Fig. 5A-F). Neither MPG nor LPG has a statistically significant correlation with egg degradation. In some studies, mites are shown to have preference for nematode larvae predation (Epsky et al., 1988; Mian et al., 1982; Muraoka and Ishibashi, 1976; Rocket, 1980; Santos et al., 1981; Walter et al., 1986). Perhaps the presence of larvae and no signs of egg degradation indicate that mites preferred to consume the larvae, not eggs. The pinworm egg prevalence of $72.7 \%$ is the highest found for all Ancestral Pueblo sites studied (Reinhard et al., 2016). In general, high prevalence could be an influence of high population density estimated to range from 700 to 1000 people (Lister and Lister, 1987). 
In Salmon Ruins there were a small number of larvae positive samples, but a considerable number of samples had mites. However, no statistically significant correlation between MPG and egg degradation was found. Pinworm EPG values were lower than Aztec Ruins Room 225. Also, compared to Aztec Ruins 225, Salmon Ruins eggs preservation was less pristine. In Fig. 3D-F we can observe that the eggshells are degraded and that there is some fungal mycelial growth that probably contributed to this degradation. Therefore, mites and fungi could have affected the eggs. This is supported by research of other authors who address parasite taphonomy in diverse contexts (Camacho et al., 2013; Leles et al., 2010; Rácz et al., 2015; Reinhard et al., 1986). Despite this observation, more analyses are required in order to understand the taphonomic issues concerning egg preservation in Salmon Ruins.

In Aztec Ruins Room 219 the results contrasted sharply to the excellent preservation in Aztec Ruins Room 225. These latrines are relatively close to each other, but exhibit divergent prevalences and preservation conditions. They represent the highest and the lowest prevalences from Ancestral Pueblo sites (Reinhard, 2008). Contrary to Aztec Ruins Room 225, Room 219's ceiling is not conserved. Abiotic factors such as water percolation could have interfered with egg preservation in the centuries post deposition as defined for medieval contexts (Rácz et al., 2015). Despite the dry environment, the site was close to the Animas River and the elevated humidity from the river could have contributed to degradation. Also, this was the only room in which MPG had a statistically significant correlation with egg degradation. This result demonstrates that mites intensely impacted egg preservation at this latrine. This biological relation was probably favored by the humidity that came from the Animas River and got into the room due to the lack of protection that would be provided if the Room's ceiling were preserved. There is a visual clue to egg predation by mites. In Fig. 4A, half of an egg is observed, which seems to have been abraded by mite's chelicerae. In this study, mite infestation is considered as a defining factor that diminished egg preservation. Mite predation on nematode larvae has been defined experimentally (Martikainen and Huhta, 1990; Muraoka and Ishibashi, 1976; Santos et al., 1981). Larvae were not present in great amounts in Room 219 which is consistent with well documented predation of mites on nematodes in diverse environments (Epsky et al., 1988; Mian et al., 1982; 
Muraoka and Ishibashi, 1976; Rocket, 1980; Santos et al., 1981; Walter et al., 1986). This is the first study that correlated the presence of mites with egg degradation in ancient samples.

In Aztec Ruins Room 219, both prevalence and taphonomic interferences demonstrate that there are different and exceptional taphonomic conditions at this latrine. This means that the prevalence data from this room underestimate the infection level of the people who used the room as a latrine in prehistory. Paleoepidemiologically, it is not possible to strictly compare parasite data from Room 219 with other Ancestral Pueblo sites, even with Room 225 located at the same site. Taphonomy shows that we are dealing with different processes, despite the latrines closely location. Therefore, we show in this study that data from the same classes of sites (Chaco Great Houses) may not be comparable paleopathologically. Indeed, coeval latrines from the same site can have pronounced parasite differences due to within site valiance in the decomposition biology. These facts, demonstrated here for the first time, signal that we must be critical in comparing data from different sites in reconstructing disease threats. Especially with mites, we must collect data on taphonomic organisms to assess the role of taphonomy in defining variation in data.

Acknowledgments - To the Conselho Nacional de Desenvolvimento Científico e Tecnológico, CNPq (AMI, grant number 307932/2014-1); Fundação de Amparo à Pesquisa do Rio de Janeiro, FAPERJ (AMI, grant number CNE E-26/202.945/2016).

\section{References}

Bryant, V.M., Reinhard, K.J., 2012. Coprolites and archaeology: the missing links in understanding human health. N. M. Mus. Nat. Hist. Sci. Bull. 57, 379-387.

Callen, E.O., Cameron, T.W.M., 1960. A prehistoric diet as revealed in coprolites. New Sci. 8 (190), 35-40.

Camacho, M., Pessanha, T., Leles, D., Dutra, J.M.F., Silva, R., Souza, S.M., de Araújo, A., 2013. Lutz's spontaneous sedimentation technique and the paleoparasitological analysis of sambaqui (shell mound) sediments. Mem. Inst. Oswaldo Cruz 108 (2), 155-159. http://dx.doi. org/10.1590/0074-0276108022013005.

Camacho, M., Araújo, A., Morrow, J.J., Reinhard, K.J., 2018. Recovering parasites from mummies and coprolites: establishing an epidemiological approach. Parasit. Vectors 11 (248). http://dx.doi.org/10.1186/s13071-018-2729-4. 
Efremov, E., 1940. Taphonomy: new branch of paleontology. Pan.-Am. Geol. 74, 81-93.

Epsky, N.D., Walter, D.E., Capinera, J.L., 1988. Potential role of nematophagous microarthropods as biotic mortality factors of entomogenous nematodes (Rhabditida: Steinernematidae, Heterorhabditidae). J. Econ. Entomol. 81 (3), 821-825. http://dx.doi.org/10.1093/jee/81.3.821.

Fugassa, M.H., Sardella, N.H., Guichón, R.A., Denegri, G.M., Araújo, A., 2008. Paleoparasitological analysis applied to museum-curated sacra from Meridional Patagonian collections. J. Archaeol. Sci. 35 (5), 1408-1411. http://dx.doi. org/10.1016/j.jas.2007.10.006.

Georgieva, S., Christensen, S., Petersen, H., Gjelstrup, P., Thorup-Kristensen, K., 2005. Early decomposer assemblages of soil organisms in litterbags with vetch and rye roots. Soil Biol. Biochem. 37 (6), 1145-1155. http://dx.doi. org/10.1016/j.soilbio.2004.11.012.

Gwinn Vivian, R., 1990. The Puebloan Period: A. D. 1120-1220. In: Gwinn Vivian, R. (Ed.), The Chacoan Prehistory of the San Juan Basin. Academic Press, San Diego, California, pp. 331-383. Gwinn Vivian, R., Hilpert, B., 2012. The Chaco Handbook: An Encyclopedic Guide, second ed. University of Utah Press, Salt Lake City.

Jaeger, L.H., Iñiguez, A.M., 2014. Molecular paleoparasitological hybridization approach as effective tool for diagnosing human intestinal parasites from scarce archaeological remains. PLoS One 9 (8), e105910. http://dx.doi. org/10.1371/journal.pone.0105910.

Leles, D., Reinhard, K.J., Fugassa, M., Ferreira, L.F., Iñiguez, A.M., Araújo, A., 2010. A parasitological paradox: why is ascarid infection so rare in the prehistoric Americas? J. Archaeol. Sci. 37 (7), 1510-1520. http://dx.doi.org/10.1016/j. jas.2010.01.011.

Lister, R.H., Lister, F.C., 1987. Aztec Ruins on the Animas: Excavated, Preserved, and Interpreted, first edition. Southwest Parks and Monuments Association, Tucson, Arizona.

Lyman, R.L., 2010. What taphonomy is, what isn't, and why taphonomists should care about the difference. J. Taphonomy. 8, 1-16.

Martikainen, E., Huhta, V., 1990. Interactions between nematodes and predatory mites in raw humus soil: a microcosm experiment. Rev. D'écologie Biol. Sol. 27, 13-20.

Mian, I.H., Godoy, G., Shelby, R.A., Rodriguez-Kábana, R., Morgan-Jones, G., 1982. Chitin amendments for control of Meloidogyne arenaria in infested soil. Nematropica 12, 71-84.

Morrow, J.J., 2016. Exploring parasitism in antiquity through the analysis of coprolites and quids from La Cueva de Los Muertos Chiquitos, Rio Zape, Durango, Mexico. In: PhD Dissertation. University of Nebraska-Lincoln, USA (AAI10102325).

Morrow, J.J., Larsen, A.S., Piombino-Mascali, D., Jankauskas, R., Kozakaitė, J., Araújo, A., Reinhard, K.J., 2014. Taphonomic considerations of a whipworm 
infection in a mummy from the Dominican church of the Holy Spirit, Vilnius, Lithuania. Int. J. Paleopathol. 7, 83-87. http://dx.doi.org/10.1016/j. ijpp.2014.08.001.

Morrow, J.J., Newby, J., Piombino-Mascali, D., Reinhard, K.J., 2016. Taphonomic considerations for the analysis of parasites in archaeological materials. Int. J. Paleopathol. 13, 56-64. http://dx.doi.org/10.1016/j.ijpp.2016.01.005.

Muraoka, M., Ishibashi, N., 1976. Nematode-feeding mites and their feeding behavior. Appl. Entomol. Zool. 11, 1-7. http://dx.doi.org/10.1303/aez.11.1.

Paseka, R., 2010. Archaeoparasitology of Chaco Canyon. In: Undergraduate Thesis Environmental Studies Program. University of Nebraska-Lincoln, USA.

Pearsall, D.M., 2016. Pollen analysis. In: Pearsall, D.M. (Ed.), Paleoethnobotany: A Handbook of Procedures, third ed. Routledge Taylor and Francis Group, New York, pp. 185-251.

Rácz, S.E., de Araújo, E.P., Jensen, E., Mostek, C., Morrow, J.J., Van Hove, M.L., Bianucci, R., Willems, D., Heller, F., Araújo, A., Reinhard, K.J., 2015. Parasitology in an archaeological context: analysis of medieval burials in Nivelles, Belgium. J. Archaeol. Sci. 53, 304-315. http://dx.doi.org/10.1016/j. jas.2014.10.023.

Read, D.S., Sheppard, S.K., Bruford, M.W., Glen, D.M., Symondson, W.O., 2006. Molecular detection of predation by soil micro-arthropods on nematodes: soil microarthropod predation. Mol. Ecol. 15 (7), 1963-1972. http://dx.doi. org/10.1111/j.1365-294X.2006.02901.X.

Reinhard, K.J., 1992. Patterns of diet, parasitism and anemia in prehistoric West North America. In: Stuart-Macadam, P., Kent, S. (Eds.), Diet, Demography and Disease: Changing Perspectives on Anemia. Aldine de Gruyter, New York, pp. 219-258.

Reinhard, K.J., 2008. Parasite pathoecology of chacoan great houses: the healthiest and wormiest Ancestral Puebloans. In: Reed, P.F. (Ed.), Salmon Ruins: Chacoan Outlier and Thirteenth-century Pueblo in the middle San Juan Region. University of Utah Press, Salt Lake City, pp. 86-95.

Reinhard, K.J., Bryant, V.M., 2008. Pathoecology and the future of coprolite studies in bioarchaeology. In: Stodder, A.W.M. (Ed.), Reanalysis and Reinterpretation in Southwestern Bioarchaeology. Arizona State University Press, Tempe, pp. 199-216.

Reinhard, K.J., Clary, K., 1986. Parasite analysis of prehistoric coprolites from Chaco Canyon, New Mexico. In: Akins, N.J. (Ed.), A Biocultural Approach to Human Burials from Chaco Canyon, New Mexico. Branch of Cultural Research, U.S. Dept. of the Interior, National Park Service, Santa Fe, New Mexico, pp. 177-186.

Reinhard, K.J., Pucu, E., 2014. Comparative parasitological perspectives on paleoepidemiological transitions: Americas and Europe. In: Zuckerman, M. (Ed.), Moving the Middle to the Foreground: Interdisciplinary Approaches to Examining the Second Epidemiological Transition. Wiley-Blackwell, Hoboken, pp. 311-326. 
Reinhard, K.J., Urban, O., 2003. Diagnosing ancient Diphyllobothriasis from Chinchorro mummies. Mem. Inst. Oswaldo Cruz 98, 191-193. http://dx.doi. org/10.1590/S0074-02762003000900028.

Reinhard, K.J., Confalonieri, U.E., Herrmann, B., Ferreira, L.F., de Araújo, A.J.G., 1986. Recovery of parasite remains from coprolites and latrines: aspects of paleoparasitological technique. Homo 37, 217-239.

Reinhard, K.J., Araújo, A., Sianto, L., Costello, J.G., Swope, K., 2008. Chinese liver flukes in latrine sediments from Wong Nim's property, San Bernardino, California: Archaeoparasitology of Caltrans District Headquarters. J. Parasitol. 94, 300-303. http://dx.doi.org/10.1645/GE-1049.1.

Reinhard, K.J., Johnson, K.L., Leroy-Toren, S., Wieseman, K., Teixeira-Santos, I., Vieira, M., 2012. Understanding the pathoecological relationship between ancient diet and modern diabetes through coprolite analysis: a case example from Antelope Cave, Mojave County, Arizona. Curr. Anthropol. 53 (4), 506-512. http://dx.doi.org/10.1086/665923.

Reinhard, K.J., Ferreira, L.F., Bouchet, F., Sianto, L., Dutra, J.M.F., Iñiguez, A., Leles, D., Le Bailly, M., Fugassa, M., Pucu, E., Araújo, A., 2013. Food, parasites, and epidemiological transitions: a broad perspective. Int. J. Paleopathol. 3 (3), 150-157. http://dx.doi.org/10.1016/j.ijpp.2013.05.003.

Reinhard, K.J., Araújo, A., Morrow, J., 2016. Temporal and spatial distribution of Enterobius vermicularis (Nematoda: Oxyuridae) in the Prehistoric Americas. Korean J. Parasitol. 54 (5), 591-603. http://dx.doi.org/10.3347/ kjp.2016.54.5.591.

Rey, L., 2008. Enterobius vermicularis e Enterobíase. In: Rey, L. (Ed.), Parasitologia. Guanabara Koogan, Rio de Janeiro, pp. 598-603.

Roberts, L., Janovy Jr., J., Nadler, S., 2013a. In: Roberts, L., Janovy Jr.J., Nadler, S. (Eds.), Parasitic Arachnids Subclass Acari, Ticks and Mites. Gerald D. Schmidt \& Larry S. Roberts' Foundations of Parasitology. McGraw-Hill International, New York, pp. 611-630.

Roberts, L., Janovy Jr., J., Nadler, S., 2013b. In: Roberts, L., Janovy Jr.J., Nadler, S. (Eds.), Nematodes: Oxyuridomorpha, Pinworms. Gerald D. Schmidt \& Larry S Roberts' Foundations of parasitology. McGraw-Hill International, New York, pp. 425-430.

Roberts, L., Janovy Jr., J., Nadler, S., 2013c. Nematodes: trichinellida and dioctophymatida, enoplean parasites. In: Roberts, L., Janovy Jr.J., Nadler, S. (Eds.), Gerald D. Schmidt \& Larry S Roberts' Foundations of parasitology. McGraw-Hill International, New York, pp. 377-390.

Roberts, L., Janovy Jr.J., Nadler, S., Roberts, L., Janovy Jr.J., Nadler, S. (Eds.), 2013. Nematodes: Ascaridomorpha, Intestinal Large Roundworms. Gerald D. Schmidt \& Larry S. Roberts' Foundations of parasitology. McGraw-Hill International, New York, pp. 411-423.

Rocket, C.L., 1980. Nematode predation by oribatid mites (Acari: Oribatida). Int. J. Acarol. 6 (3), 219-224. http://dx.doi.org/10.1080/01647958008683222. 
Santos, P.F., Phillips, J., Whitford, W.G., 1981. The role of mites and nematodes in early stages of buried litter decomposition in a desert. Ecology 62 (3), 664669. http://dx.doi.org/10.2307/1937734.

Schillaci, M.A., Stojanowski, C.M., 2002. Investigating social organization at Aztec Ruins using determinant ratio analysis. In: Wiseman, R.N., O'Laughlin, T.C., Snow, C.T. (Eds.), Forward Into the Past: Papers in Honor of Teddy Lou and Francis Stickney. Archaeological Society of New Mexico, Albuquerque, New Mexico, pp. 93-104.

Sorg, M., Haglund, W., 2002. Advancing forensic taphonomy: purpose, theory, and process. In: Haglund, W.D., Sorg, M.H. (Eds.), Advances in Forensic Taphonomy - Method, Theory, and Archaeological Perspectives. CRC Press, Boca Raton, Florida, pp. 3-30.

Walter, D.E., Hudgens, R.A., Freckman, D.W., 1986. Consumption of nematodes by fungivorous mites, Tyrophagus spp. (Acarina: Astigmata: Acaridae). Oecologia 70 (3), 357-361. http://dx.doi.org/10.1007/BFo0379497. 